D.O.I.: $10.3895 / \mathrm{S} 1808-04482013000400004$

\title{
MUDANÇA ORGANIZACIONAL IMPULSIONADA PELA PRODUÇÃO MAIS LIMPA
}

\section{ORGANIZATIONAL CHANGE DRIVEN BY CLEANER PRODUCTION}

\author{
Michele Otobelli Bertéli ${ }^{1}$; Paulo Fernando Pinto Barcellos ${ }^{2}$; Margareth Rodrigues de Carvalho \\ Borella $^{3}$ \\ ${ }^{1}$ Universidade de Caxias do Sul - Caxias do Sul - RS - Brasil \\ micheleberteli@gmail.com \\ ${ }^{2}$ Universidade de Caxias do Sul - Caxias do Sul - RS - Brasil \\ PFPBarce@ucs.br \\ ${ }^{3}$ Universidade de Caxias do Sul - Caxias do Sul - RS - Brasil \\ mrcborel@ucs.br
}

\section{Resumo}

As empresas como transformadoras de matérias-primas em produtos possuem grande responsabilidade na proteção, manuseio e utilização dos recursos naturais disponíveis. Desta forma, todos os esforços em busca de promover o desenvolvimento sustentável devem ser prioritários. Neste contexto, o objetivo deste artigo é descrever e avaliar o impacto da utilização de técnicas de Produção mais Limpa no desempenho dos setores de serraria e de fabricação de caixas para embalagens (caixaria) em uma empresa fabricante de motores elétricos. A pesquisa é de abordagem qualitativa com objetivo descritivo. O procedimento técnico utilizado foi o estudo de caso. Da análise dos resultados obtidos, pode-se concluir que o uso desta ferramenta foi decisivo para a redução de resíduos dos processos produtivos, ressaltando-se os benefícios ambientais $e$ econômicos da implementação da técnica de Produção mais Limpa e como esta impulsionou a mudança organizacional na organização pesquisada, principalmente pelo envolvimento de todos os funcionários do processo e pelas pequenas mudanças implantadas no decorrer do projeto.

Palavras-chave: produção mais limpa; mudança organizacional; desenvolvimento sustentável.

\section{Introdução}

A acirrada competitividade gerada pelo mercado impõe às empresas aprimorarem continuamente seus produtos e os processos necessários para a fabricação, orientando-se cada vez mais para a sustentabilidade interna e dos stakeholders.

A natureza do ambiente em que a organização está inserida é quase sempre conceituada como algo a ser adaptado ou controlado. Dessa forma, a organização pode adaptar sua estrutura, seu sistema de informações, seus modelos administrativos e de relações humanas, sua tecnologia, seus produtos, seus valores e suas normas, ou pode, ainda, adaptar sua definição de ambiente. 
Adotando processos ecoeficientes, as empresas podem gerar uma redução de custos no longo prazo, reduzir o risco, melhorar o uso das receitas, produzir mais com menos recursos naturais e aumentar sua competitividade e a margem de lucro. Dois dos programas mais familiares para alcançar a ecoeficiência são os Sistemas de Gestão Ambiental (SGAs) e programas de Produção mais Limpa (P+L) (SCHNEIDER; NEHME; BEN, 2006).

A Produção mais Limpa promove a construção de um ambiente favorável para a mudança organizacional, uma vez que fomenta a criação de um grupo direcionado para o mesmo objetivo e de forma estruturada, estimula todos a refletir, analisar, avaliar as possíveis soluções e a compartilhar do mesmo sentimento de mudança.

O presente trabalho insere-se neste contexto, tendo como objetivo avaliar o impacto da utilização de técnicas de Produção mais Limpa no desempenho dos setores de serraria e de fabricação de caixas para embalagens (caixaria) em uma empresa fabricante de motores elétricos, bem como o efeito da Produção mais Limpa sobre a mudança organizacional.

\section{Produção mais limpa}

O conceito de Produção mais Limpa (P+L) foi definido pelo PNUMA (2004) como sendo "a aplicação contínua de uma estratégia ambiental preventiva integrada aos processos, produtos e serviços para aumentar a ecoeficiência e reduzir os riscos ao homem e ao meio ambiente". Este conceito é confirmado em artigos internacionais sobre o tema, publicados no Journal of Cleaner Production (BAAS, 2007; BERKEL, 2007). Aplica-se a:

- Processos produtivos: inclui conservação de recursos naturais e energia, eliminação de matérias-primas tóxicas e redução da quantidade e da toxicidade dos resíduos e emissões;

- Produtos: envolve a redução dos impactos negativos ao longo do ciclo de vida de um produto, desde a extração de matérias-primas até a sua disposição final;

- Serviços: estratégia para a incorporação de considerações ambientais no planejamento e entrega dos serviços.

A abordagem $\mathrm{P}+\mathrm{L}$ se espalhou pelo mundo através de apresentações pessoais, conferências, esforços promocionais de organizações como o programa das Nações Unidas para o Ambiente (UNEP) e Nações Unidas para o Desenvolvimento Industrial (UNIDO). Cada país adotou diferentes estratégias para a disseminação das práticas deste conceito. Na Europa ocorreu por intermédio das organizações como a United Nations National Cleaner Production Centres (NCPC), na China se deu através de diferentes agências do governo (incluindo certificação e auditorias) enquanto que no Brasil a iniciativa foi dada pelo SENAI (Serviço Nacional de Aprendizagem Industrial) (BAAS, 2007; ZENG et al, 2010; PNUMA, 2004). 
A $\mathrm{P}+\mathrm{L}$ é uma estratégia aplicada na produção e nos produtos a fim de economizar e maximizar a eficiência do uso de energia, matérias-primas e água e ainda minimizar ou reaproveitar resíduos gerados. Os procedimentos são simples e econômicos, podendo chegar a um número maior de empresas, pois a análise é feita compreendendo apenas a unidade fabril em questão, sem considerar a cadeia produtiva como um todo, ou seja, fornecedores e clientes não são foco do estudo (HINZ; VALENTINA; FRANCO, 2007).

De acordo com as entidades, ao praticarem ações de $\mathrm{P}+\mathrm{L}$, as empresas podem alcançar o duplo objetivo de poluir menos e gerar ganhos econômicos, resultantes de melhorias de seus processos produtivos e redução de gastos no tratamento e disposição final de rejeitos (PNUMA, 2004). Zeng et al (2010) acrescentam que através da prevenção da poluição, as empresas podem obter poupanças significativas, resultando em uma vantagem de custo em relação aos concorrentes.

As vantagens significativas advindas da adoção dos princípios e técnicas do $\mathrm{P}+\mathrm{L}$ aumentam as expectativas de mudanças para os setores produtivos. As fortes tendências do uso dessas técnicas são uma realidade para organizações que almejam elevar sua competitividade, entretanto, o sistema fim de tubo ainda persiste em muitos processos e empresas. Baas (2007) coloca que em pesquisas de gestão ambiental realizada nas empresas holandesas mostrou que gestores de empresas, muitas vezes, consideram fim de tubo e Produção mais Limpa como sendo a mesma coisa, sendo assim, é importante ressaltar a diferença entre $\mathrm{P}+\mathrm{L}$ e técnicas de fim de tubo.

A P+L é uma ação preventiva que busca evitar, por exemplo, a geração de resíduos por meio do aproveitamento das matérias-primas utilizadas durante o processo produtivo. As técnicas fim de tubo são ações que apenas ajudam a diminuir o impacto ambiental de determinados resíduos, aos dar-lhes tratamento. Portanto, o fim de tubo só é válido para tratar aqueles resíduos que não puderam ser evitados no processo, sendo considerado uma alternativa de remediação, enquanto que P+L é uma proposta de solução (CNTL, 2007).

Berkel (2007) acrescenta que a metodologia de Produção mais Limpa não é uma solução rígida, e sim um modelo que oportuniza práticas de prevenção, trazendo melhorias para o negócio, reduzindo custos e riscos, aumentando a eficiência, produtividade e a rentabilidade.

Conforme a companhia de Tecnologia de Saneamento Ambiental (CETESB, 2001), adotando as práticas de $\mathrm{P}+\mathrm{L}$ é possível atingir os seguintes benefícios:

- Redução da responsabilidade das empresas geradoras de contaminação a longo prazo num mesmo local, ainda que atendendo à legislação;

- Aumento da rentabilidade do negócio;

- Melhoria da imagem corporativa e apoio em ações de marketing;

- Redução dos custos de produção;

- Aumento da produtividade; 
- Retorno do capital investido nas melhorias em curto período;

- Expansão no mercado dos produtos da empresa;

- Uso mais racional da água, da energia e das matérias-primas;

- Redução no uso das substâncias tóxicas;

- Redução da geração de resíduos, efluentes e emissões; e de gastos com seu tratamento e destinação final;

- Motivação dos funcionários à participação no aporte de ideias;

- Redução dos riscos de acidentes ambientais e ocupacionais;

- Melhoria do relacionamento com a comunidade e com os órgãos públicos.

Com base nestes aspectos, é possível utilizar técnicas/medidas entendidas como de Produção mais Limpa, visando à minimização de resíduos. Estas técnicas estão agrupadas, representando níveis diferenciados de aplicação de $\mathrm{P}+\mathrm{L}$, conforme pode ser visto na Figura 1.

Figura 1 - Fluxograma para o estabelecimento de prioridades de $\mathrm{P}+\mathrm{L}$

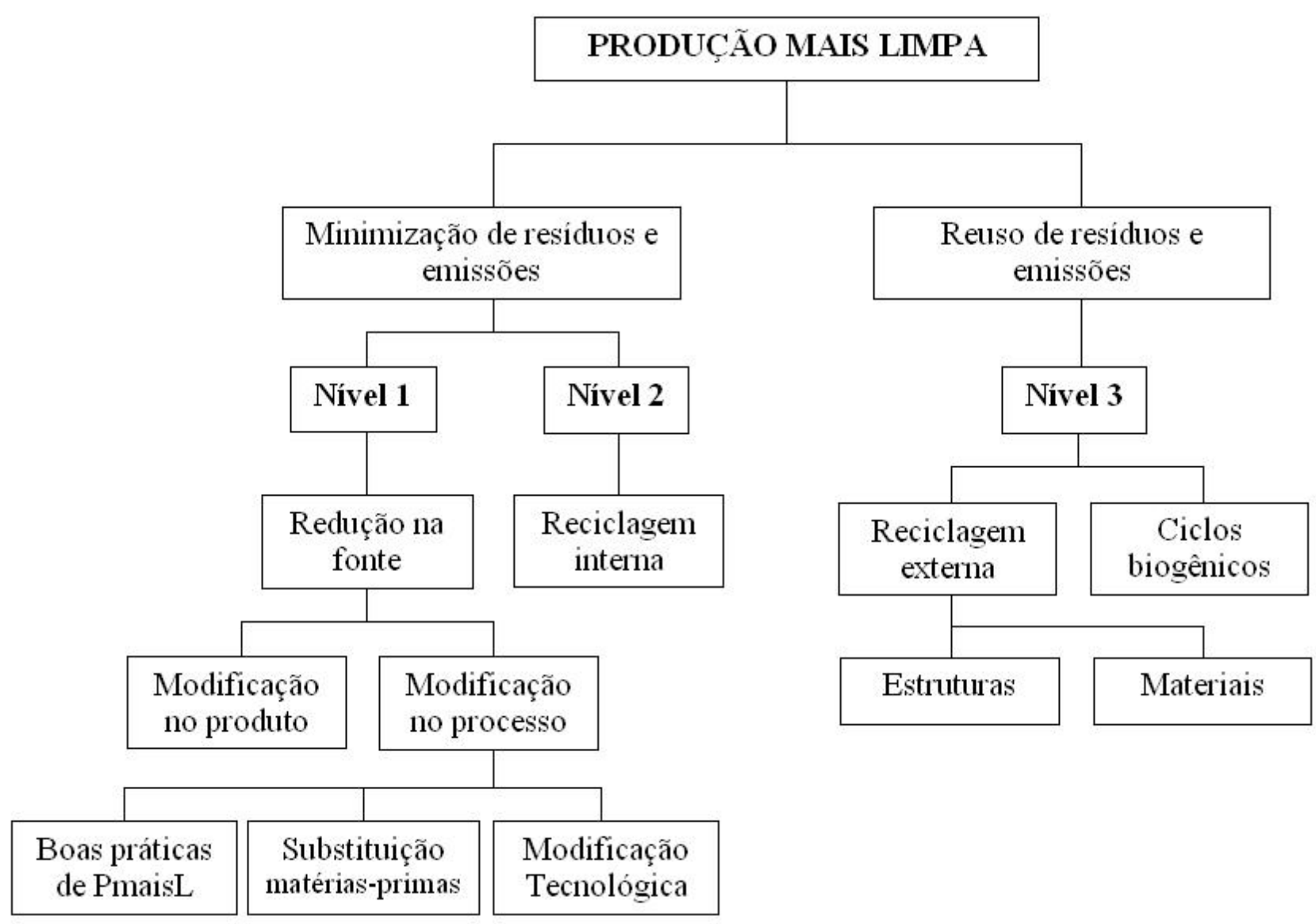

Fonte: Adaptado de Hillig, Schneider e Pavoni (2004)

A sistematização das ações busca, prioritariamente, a prevenção aos impactos ambientais a partir da redução de resíduos, de efluentes e de emissões na fonte (nível 1), ou seja, o ideal é evitar a geração de resíduos, e quando esses não podem ser evitados, reintegrá-los ao processo de 
produção (nível 2). Na impossibilidade de reutilização de resíduos, as medidas para reciclagem externa (HILLIG; SCHNEIDER; PAVONI, 2004) devem, então, ser adotadas (nível 3).

Em síntese, a $\mathrm{P}+\mathrm{L}$ faz com que as matérias-primas sejam mais bem utilizadas e o processo otimizado. Desta forma, tem-se um aumento do produto e uma diminuição dos resíduos, o que traz um imediato resultado financeiro para a empresa - benefício econômico. O benefício ambiental é decorrente da diminuição do volume de resíduos.

As oportunidades para a redução do desperdício e prevenção da poluição podem ser identificadas em várias etapas do processo, segundo Hillig, Schneider e Pavoni (2004), e envolve algumas das ações abaixo:

- Nova concepção de produto;

- Alteração da sequência ou do processo fabril;

- Eventual substituição de matérias-primas e subsidiárias por outras menos poluentes;

- Purificação das matérias-primas que entram nas fábricas;

- Reciclagem interna de resíduos, de água e de outras substâncias;

- Aumento da eficiência na geração e uso de energia;

- Escolha criteriosa das técnicas de operação;

- Controle e otimização do processo.

A Produção mais Limpa tende a contribuir para a eficiência das empresas, a competitividade dos produtos, e busca a ecoeficiência, hoje perseguida em todo o mundo, e considerada a melhor forma de compatibilizar os processos produtivos com os recursos naturais do planeta, pois visa a racionalização do uso de energia, de água e de todas as matérias-primas usadas pelos diversos setores de produção. Para Berkel (2007) pode-se abordar ecoeficiência como o lado estratégico do negócio, enquanto que Produção mais limpa é o lado operacional.

A implementação da estratégia da $\mathrm{P}+\mathrm{L}$ exige que todo o processo produtivo seja avaliado. Esta avaliação está baseada na realização de balanços de massa e energia, para avaliar os processos e produtos. Com isso, identificam-se oportunidades de melhoria que levam em conta aspectos técnicos, ambientais e econômicos, definindo e implantando-se indicadores para monitoramento (CEBDS, 2001).

As intervenções podem assumir diferentes formas, sendo que o mais comum, em projetos de $\mathrm{P}+\mathrm{L}$, são as intervenções limitadas à tecnologia. As avaliações do processo de produção são a base para as opções relativas a mudanças no processo produtivo. Para tanto, existe um intercâmbio mútuo de lições aprendidas, vitais para a criação e uso de sinergia, que precisam ser geridos. Sendo assim, os processos de aprendizagem desempenham um papel importante para o processo de mudança. 
A capacidade e a potencialidade de romper rotinas existentes é parte de uma eventual mudança organizacional, para tanto, deve-se realizar uma avaliação interna na organização, verificando se a estrutura e a cultura organizacional, além de entender o conceito de produção mais limpa, estão dispostas as possibilidades de mudança na organização (BAAS, 2007).

\section{Mudança organizacional}

A revisão da bibliografia revela diferentes conceitos sobre mudança organizacional. Observa-se que a maioria dos textos refere-se a prescrições sobre gestão do processo de implementação da mudança, conforme definições apresentadas no Quadro 1.

\begin{tabular}{|c|c|}
\hline \multicolumn{2}{|c|}{ Quadro 1 - Definições teóricas sobre mudança organizacional } \\
\hline Porras e Robertson (1992) & $\begin{array}{c}\text { Definaño } \\
\text { objetivando mudança planejada do ambiente de trabalho com o objetivo de elevar o } \\
\text { desenvolvimento individual e o desempenho organizacional. }\end{array}$ \\
\hline Nadler, Shaw e Walton (1994) & $\begin{array}{c}\text { Resposta da organização às transformações que vigoram no ambiente, com o intuito } \\
\text { de manter a congruência entre os componentes organizacionais (trabalho, pessoas, } \\
\text { arranjos/estrutura e cultura). }\end{array}$ \\
\hline Ford e Ford (1995) & $\begin{array}{c}\text { Acontecimento temporal estritamente relacionado a uma lógica, ou ponto de vista } \\
\text { individual, que possibilita às pessoas pensarem e falarem sobre a mudança que } \\
\text { percebem. }\end{array}$ \\
\hline Robbins (1999) & $\begin{array}{c}\text { São atividades intencionais, pró-ativas e direcionadas para a obtenção das metas } \\
\text { organizacionais. }\end{array}$ \\
\hline Wood Jr. (2000) & $\begin{array}{c}\text { Qualquer transformação de natureza estrutural, estratégica, cultural, tecnológica, } \\
\text { humana ou de outro componente, capaz de gerar impacto em partes ou no conjunto } \\
\text { da organização. }\end{array}$ \\
\hline Bruno-Faria (2003) & $\begin{array}{c}\text { É qualquer alteração, planejada ou não, ocorrida na organização, decorrente de } \\
\text { fatores internos e/ou externos à organização que traz algum impacto nos resultados } \\
\text { e/ou nas relações entre as pessoas no trabalho. }\end{array}$ \\
\hline
\end{tabular}

Fonte: Autoria própria (2011)

O Quadro 1 revela certa heterogeneidade, no entanto, o que pode ser encontrado como elemento comum é a necessidade de planejamento da mudança, o seu caráter de resposta às demandas do meio, seu objetivo de aumento do desempenho organizacional, e a sua abrangência a vários componentes organizacionais.

O modelo clássico do processo de mudança organizacional é baseado na proposta de Kurt Lewin para a mudança social. Lewin (1951) notou que a mudança persistia apenas durante um curto intervalo de tempo até que as pessoas e as condições revertessem ao seu estado anterior. De acordo com o autor, para que as mudanças sejam bem-sucedidas, as organizações devem seguir três etapas:

- Descongelamento: responsabilidade gerencial de preparar uma situação para a mudança;

- Mudança: tomar medidas para realmente modificar uma situação;

- Recongelamento: reforço positivo dos resultados desejados e apoio extra quando dificuldades são encontradas. 
Apesar de ter sido concebido em 1951, este modelo apresenta-se popularmente, podendo ser encontrado em diversas versões, enriquecido pela visão de diferentes especialistas do desenvolvimento organizacional. Outros modelos tratam da forma como a mudança ocorre, e se preocupam com sua implementação e em como gerenciá-la.

Kotter (1995), durante um período de dez anos, 1985 a 1995, observou mais de cem organizações que tentavam tornar-se significativamente melhores competidores. As empresas tinham recorrido a diversas abordagens com o intuito de fazer mudanças fundamentais na condução de seus negócios para enfrentar um ambiente de negócio novo e desafiador. A pesquisa mostra que a maioria desses esforços não teve sucesso, fracassando em seus esforços de mudança. Os erros fatais identificados pelo autor são:

- Permitir complacência excessiva;

- Falhar na criação de uma coalizão administrativa forte;

- Subestimar o poder da visão corporativa;

- Comunicar a visão de forma ineficiente;

- Permitir que obstáculos bloqueiem a nova visão;

- Falhar na criação de vitórias de curto prazo;

- Declarar vitória prematuramente;

- Negligenciar a incorporação sólida das mudanças à cultura corporativa.

A lição aprendida é de que o processo de mudança dá-se em etapas que requerem tempo. $\mathrm{O}$ modelo de Kotter se desenvolve, então, a partir da análise desses erros, apresentando uma sequência de oito etapas para preveni-los ou eliminá-los. Kotter (1995) indica que esses são os oito passos necessários para a implementação efetiva de um processo de mudança. Para o autor, as mudanças de sucesso de qualquer magnitude passam por esses oito estágios, usualmente na sequência apresentada. Embora normalmente as organizações operem em múltiplas fases simultaneamente, o autor acredita que pular, mesmo que apenas um dos passos, ou se afastar da ordem proposta sem uma base sólida pode criar dificuldades para aquele encarregado de conduzir o processo de mudança. As etapas foram divididas em oito passos, identificados como:

- Passo 1: aumentar ou criar a urgência;

- Passo 2: construir a equipe de orientação para conduzir a mudança;

- Passo 3: desenvolver a visão certa;

- Passo 4: comunicar-se para promover a compra;

- Passo 5: empowerment para a ação;

- Passo 6: propiciar vitórias a curto prazo;

- Passo 7: não permitir o desânimo; 
- Passo 8: inserir as mudanças na cultura organizacional.

De acordo com Kotter e Cohen (2002), as pessoas mudam menos com base em análises que moldam seu raciocínio do que por força da visão de uma verdade que influencia seus sentimentos. Nesta lógica, não adianta criar ações que geram análises e decisões, é necessário a criação de fatos que gerem emoções e mudam a forma das pessoas de se posicionar diante das situações. Dessa forma, o desafio central de todos os oito passos do processo de mudança é mudar o comportamento das pessoas. Não se trata de estratégia, nem de sistemas, nem de cultura; o âmago do problema é comportamental: o que as pessoas fazem e a necessidade de mudanças significativas no que fazem.

Segundo os autores Kotter e Cohen (2002), no livro "O coração da Mudança”, as pessoas agem somente se vêem sentido em suas ações, e sendo assim, as pessoas envolvem-se emocionalmente e seus comportamentos mudam. Ainda conforme os mesmos autores, a turbulência jamais cessará. As melhores evidências mostram que as organizações vitoriosas continuarão a enfrentar essa instabilidade inexorável, seguindo o processo de oito passos para promover a adaptação e a transformação. O maior desafio isolado ao longo do processo é mudar o comportamento das pessoas. A chave para essa mudança de comportamento está no tripé ver, sentir e mudar.

Adotar estratégias de mudança que obtenham sucesso envolve compreender aspectos do ambiente, dos indivíduos e da organização como um todo. Desta forma, identificar variáveis do contexto que estariam provocando as mudanças, sejam contínuas ou descontínuas, apresenta-se como uma vantagem para os gerenciadores da mudança, na medida em que esse conhecimento poderia permitir o manejo e a implantação da mudança, o aumento da eficácia organizacional e de sua chance de sobrevivência. Robbins (1999) apresenta seis aspectos específicos que atuam como desencadeadores de mudança:

- A natureza da força do trabalho;

- A tecnologia;

- Os choques econômicos;

- A concorrência;

- As tendências sociais;

- A política mundial.

Esses aspectos estariam presentes no cotidiano organizacional de forma mais ou menos aguda em determinados momentos, mas constantemente exerceriam pressão sobre a organização.

No intuito de responder efetivamente às demandas do ambiente, Nadler, Shaw e Walton (1994) acreditam que as organizações devem investir e se preocupar com o aumento da qualidade e do valor do cliente; a diminuição dos custos de coordenação interna; o aumento da inovação 
competitiva; a redução do tempo de resposta ao mercado; a motivação dos membros para contribuírem de forma efetiva; a capacidade de gerenciar a mudança de maneira rápida e o encontro de uma real vantagem competitiva.

Para Pettigrew (1987) os fatores capazes de precipitar mudanças organizacionais são basicamente extraorganizacionais, ou seja, mudanças no ambiente de negócios e recessão econômica. No entanto, outros aspectos também devem ser analisados num processo de mudança:

- A inércia organizacional;

- As mudanças de estrutura da organização;

- O ambiente em que esta se insere.

Dessa forma, pode-se apontar que os causadores de mudança organizacional possuem basicamente duas fontes; o ambiente externo e as características da própria organização. Por aspectos ligados ao ambiente externo entende-se a política mundial, crises e tendências macroeconômicas, mudanças legais e regulamentação, recessão econômica, competição e inovação tecnológica; e por características da própria organização entende-se o desempenho, características pessoais dos gerentes, natureza da força do trabalho, crescimento organizacional e descontinuidade na estrutura organizacional.

\section{A pesquisa}

Atribui-se como objetivo desta pesquisa avaliar o impacto da utilização de técnicas de Produção mais Limpa no desempenho dos setores em estudo, bem como o efeito da Produção mais Limpa sobre a mudança organizacional. Sendo assim, a pesquisa é de abordagem qualitativa com objetivo descritivo, pois de acordo com Cervo, Bervian e Silva (2007, p. 61) a pesquisa descritiva “observa, registra, analisa e correlaciona fatos ou fenômenos (variáveis) sem manipulá-los”.

O procedimento técnico utilizado para a pesquisa foi o estudo de caso, pois, conforme Martins e Theóphilo (2009, p. 62) "trata-se de uma investigação empírica que pesquisa fenômenos dentro do seu contexto real (pesquisa naturalística), onde o pesquisador não tem controle sobre eventos e variáveis". Busca-se aprender o todo de uma situação de forma criativa, descrevendo, compreendendo e interpretando a complexidade de um caso real. De acordo com Yin (2005, p. 32) "um estudo de caso é uma investigação empírica que investiga um fenômeno contemporâneo dentro de seu contexto da vida real, especialmente quando os limites entre o fenômeno e o contexto não estão claramente definidos".

\subsection{A organização pesquisada}

Este estudo de caso foi desenvolvido na empresa Alpha, localizada no estado do Rio Grande do Sul. O grupo é composto por três unidades produtivas que juntas ultrapassam o faturamento de 
R\$ 300 milhões ao ano e possui cerca de dois mil funcionários que trabalham numa área construída de $59.000 \mathrm{~m}^{2}$.

A empresa é um dos principais grupos brasileiros a fornecer soluções customizadas em eficiência energética e peças de fundição de alto grau de segurança. Suas unidades possuem o compromisso de trabalhar pelo aprimoramento contínuo dos produtos e serviços prestados. Sempre em busca de novas tecnologias e métodos para garantir a satisfação, a flexibilidade e a competitividade de seus clientes.

A escolha desta organização para o desenvolvimento do trabalho se deu em função da conveniência, pois um dos autores trabalhou e estagiou na organização durante o período de estudo e pode aplicar as técnicas de Produção mais Limpa e observar o resultado que a implantação trouxe para a organização. A pesquisa ocorreu em dois setores específicos da empresa, a serraria e a caixaria, responsáveis pela produção das embalagens de madeira utilizadas em todas as unidades do grupo, tanto para o mercado nacional como internacional, sendo que cada unidade tem seus produtos específicos e necessitam de embalagens diferenciadas para protegerem seus produtos. Estes setores operam em dois turnos de produção, com um total de 38 funcionários.

\subsection{A coleta de dados}

Para o desenvolvimento do trabalho foram aplicadas técnicas de $\mathrm{P}+\mathrm{L}$ visando alcançar a ecoeficiência do processo, a melhoria de desempenho em redução de resíduos e custos, bem como o aumento do aproveitamento da madeira extraída. A aplicação baseou-se na metodologia desenvolvida pelo CNTL (2007). Esta metodologia segue cinco etapas de implantação, subdivididas em vinte tarefas, conforme apresentado na Figura 2. A coleta de dados se deu por formulários e pesquisa documental. O período de abrangência da coleta de dados do estudo contempla março de 2007 a março de 2010, enquanto que a atualização financeira foi realizada em janeiro de 2012.

Figura 2 - Etapas da implantação de $\mathrm{P}+\mathrm{L}$

\begin{tabular}{|c|}
\hline ETAPA 1: Planejamento e organização \\
$1^{\circ}$ Passo: Obter o comprometimento da gerência \\
$2^{\circ}$ Passo: Organizar o ecotime \\
$3^{\circ}$ Passo: Estabelecer metas \\
$4^{\circ}$ Passo: Identificar barreiras e apresentar soluções \\
ETAPA 2: Pré-avaliação \\
$5^{\circ}$ Passo: Desenvolver um fluxograma de processo \\
$6^{\circ}$ Passo: Avaliar as entradas e as saídas \\
$7^{\circ}$ Passo: Determinar os focos de avaliação de $\mathrm{P}+\mathrm{L}$ \\
ETAPA 3: Avaliação \\
$8^{\circ}$ Passo: Organizar um balanço de material \\
$9^{\circ}$ Passo: Avaliação das causas \\
$10^{\circ}$ Passo: Gerar opção de P+L \\
$11^{\circ}$ Passo: Seleção de opções \\
$12^{\circ}$ Passo: Avaliação preliminar \\
$13^{\circ}$ Passo: Avaliação técnica \\
$14^{\circ}$ Passo: Avaliação econômica \\
ETAPA 4: Estudo de viabilidade
\end{tabular}




\begin{tabular}{|c|}
\hline $15^{\circ}$ Passo: Avaliação ambiental \\
$16^{\circ}$ Passo: Selecionar opções \\
ETAPA 5: Implementação \\
$17^{\circ}$ Passo: Preparar um plano de $\mathrm{P}+\mathrm{L}$ \\
$18^{\circ}$ Passo: Implementar ações de $\mathrm{P}+\mathrm{L}$ \\
$19^{\circ}$ Passo: Monitorar e avaliar \\
$20^{\circ}$ Passo: Sustentar atividades de $\mathrm{P}+\mathrm{L}$ \\
\hline
\end{tabular}

Fonte: CNTL (2007)

\subsection{Descrição do caso}

O processo de fabricação dos engradados de madeira inicia-se na extração das toras na unidade de reflorestamento pertencente à empresa. Entretanto, o estudo foi delimitado nos setores de serraria e caixaria, responsáveis pela confecção das embalagens de madeira utilizadas por todas as unidades de negócio da empresa.

Na Etapa 1 de planejamento e organização, buscou-se o apoio e a participação da direção e gerência da empresa, realçando que a aplicação de $\mathrm{P}+\mathrm{L}$ melhora a eficiência do processo e a qualidade do produto, contribuindo para a inovação industrial e a competitividade. $\mathrm{O}$ ecotime foi formado com a representação de todos os setores da empresa que se envolvem com a área de estudo. Em seguida, foram estabelecidas as metas e o objetivo do programa na empresa. A meta definida visa aumentar a vida útil das toras da unidade de reflorestamento da empresa. O objetivo foi aplicar técnicas de Produção mais Limpa nos setores de serraria e caixaria para aumentar a eficiência dos processos, reduzir os resíduos gerados e consequentemente melhorar a utilização da matéria-prima nestes setores. Por fim, identificou-se as barreiras que pudessem impedir ou retardar a avaliação da $\mathrm{P}+\mathrm{L}$, encontrando soluções para as mesmas.

Durante 15 anos, as atividades dos setores de serraria e caixaria foram conduzidas por empresas terceirizadas e dentro do parque fabril da empresa. No ano de 2004, o empreendedor que adquiriu a unidade de motores elétricos integrou esses setores à gestão da empresa, mantendo a mesma equipe de funcionários. De uma forma geral, os funcionários dos setores de serraria e caixaria sentiam-se inferiores aos demais setores da empresa devido às instalações, aos salários e ao próprio trabalho. Nesse sentido, o ecotime sentiu necessidade de promover melhorias no ambiente de trabalho destes setores, uma vez que o envolvimento e o comprometimento dos funcionários são importantes para o desenvolvimento do projeto. Dessa forma, a equipe compartilhou o problema com o diretor superintendente que, atento às insatisfações, decidiu reunir os funcionários dos setores para conhecer as condições das instalações, os funcionários, e principalmente, poder explanar sobre a importância de suas atividades para a empresa. Uma semana após essa reunião, o projeto foi apresentado para toda a equipe dos setores envolvidos.

Alguns indicadores foram estabelecidos para auxiliar na coleta de dados e de informações e para monitorar os resultados das mudanças que foram sendo implementadas. Estes indicadores são: produtividade, quantidade de resíduos gerados e aproveitamento de madeira. 
Na Etapa 2 de pré-avaliação, desenvolveu-se um fluxograma de processo dos setores de serraria e caixaria, mostrando todos os passos pelos quais passa a matéria-prima até formar o produto. As ações para Produção mais Limpa que não exigiam investimentos foram realizadas gradativamente para motivar o ecotime e os funcionários dos respectivos setores. Alterações no projeto do produto foram propostas e realizadas, conforme descrito:

- Novo dimensionamento da espessura da tábua;

- Padronização das larguras das tábuas;

- Inclusão de reforço com cantoneiras triangulares;

- Diminuição da largura das tábuas dos pallets.

Todos os desenhos, documentos e procedimentos foram modificados conforme as ações tomadas. Também foram criadas instruções de trabalho no setor serraria, até então inexistentes, detalhando o novo padrão de espessuras e larguras das tábuas a serem serradas.

Na Etapa 3 de avaliação, foi originado e consolidado o balanço de material, com base no princípio da conservação de massa e energia. Identificado o setor serraria como o setor a ser priorizado, foi realizado um balanço específico na atividade de serrar. Na Tabela 1 tem-se o resultado da medição do balanço de massa realizado na serraria durante o período de uma semana. Os valores foram projetados para o período de um ano. O custo da matéria-prima (tora) é de R\$ 97,58 por metro cúbico. Esse valor foi considerado para calcular o custo do resíduo da matériaprima, demonstrado na Tabela 1.

Tabela 1 - Balanço de massa realizado na atividade "serrar"

\begin{tabular}{ccccccc}
\hline \multirow{2}{*}{ Resíduos } & $\begin{array}{c}\text { Quantidade } \\
\text { Anual (ton) }\end{array}$ & $\begin{array}{c}\text { Custo do Resíduo } \\
\mathbf{x} \mathbf{M P}(\mathbf{1})(\mathbf{A})\end{array}$ & $\begin{array}{c}\text { Custo de } \\
\text { Transporte } \\
(\mathbf{B})\end{array}$ & $\begin{array}{c}\text { Valor de } \\
\text { Venda }(\mathbf{2}) \\
(\mathbf{C})\end{array}$ & $\begin{array}{c}\text { CUSTO } \\
\text { TOTAL } \\
(\mathbf{A}+\mathbf{B}+\mathbf{C})\end{array}$ & DESTINO \\
\hline Costaneiras & $2.257,89$ & $\mathrm{R} \$ 220.324,91$ & $\mathrm{R} \$ 3.120,00$ & $\mathrm{R} \$ 0,00$ & $\mathrm{R} \$ 223.444,91$ & Doado \\
Serragem & $1.562,06$ & $\mathrm{R} \$ 152.425,81$ & $\mathrm{R} \$ 0,00$ & $\mathrm{R} \$ 35.927,38$ & $\mathrm{R} \$ 116.498,43$ & Vendido \\
Cascas & 71,00 & $\mathrm{R} \$ 6.928,18$ & $\mathrm{R} \$ 0,00$ & $\mathrm{R} \$ 1.633,00$ & $\mathrm{R} \$ 5.295,18$ & Vendido \\
\hline
\end{tabular}

(1) Custo do resíduo associado à quantidade de matéria-prima (MP), em tonelada

(2) Relativo ao ganho com a venda dos resíduos

Fonte: Autoria própria (2011)

A serragem e as cascas são vendidas para uma empresa produtora de celulose pelo preço de $\mathrm{R} \$ 23,00$ a tonelada. A retirada dos resíduos do silo e o transporte são realizados por essa empresa compradora, não gerando custo para a companhia. As costaneiras são disponibilizadas no pátio da empresa vizinha, sob a forma de doação, para serem utilizadas na caldeira. Em contrapartida, o vapor gerado é fornecido para o refeitório de ambas as empresas. Para o cálculo do custo de disposição das costaneiras foi considerado o valor da mão de obra do motorista da empilhadeira para transportar os resíduos.

O ecotime organizou uma expedição com os funcionários da serraria e da caixaria da empresa para que os mesmos pudessem conhecer a etapa inicial do processo que ocorre na unidade 
de reflorestamento. Durante o dia inteiro eles acompanharam o cultivo do solo, o plantio das mudas e principalmente a derrubada e transporte das toras na unidade. Nessa mesma ocasião, o ecotime mostrou, durante o intervalo da manhã, os resultados do projeto alcançados até o momento; e, na parte da tarde, apresentou um vídeo de sensibilização sobre atitude e preservação do meio ambiente, fazendo uma interrelação com o trabalho que estava sendo desenvolvido com o comprometimento de todos.

Na Etapa 4, estudo de viabilidade, a alternativa de aquisição de uma máquina para fazer o aproveitamento das costaneiras, foi submetida a um estudo de viabilidade técnica (considerando o processo, a produtividade e a segurança), avaliação econômica (considerando o período de recuperação do investimento - payback, o valor presente líquido - VPL e taxa interna de retorno TIR), e avaliação ambiental (determinando os impactos positivos ou negativos das alternativas propostas ao meio ambiente).

Na Etapa 5 de implementação da metodologia de produção mais limpa, foi elaborado um plano de $\mathrm{P}+\mathrm{L}$ contendo todas as possibilidades de melhorias elencadas pelo ecotime. A diretoria da empresa aprovou a compra da máquina para fazer o reaproveitamento das costaneiras, bem como todas as opções que não exigiam investimentos maiores. As demais opções foram acrescentadas no plano de investimentos da empresa.

A alta administração da empresa sensibilizou-se com o envolvimento e a participação dos funcionários desses setores no projeto, o que desencadeou iniciativas junto ao setor de Recursos Humanos para trabalhar a motivação das pessoas. Ações específicas foram concretizadas, tal como a revisão do enquadramento destes funcionários no plano de cargos e salários. A empresa também investiu em melhorias importantes no ambiente de trabalho, principalmente nas instalações e nos equipamentos de segurança utilizados.

\section{Apresentação e discussão dos resultados}

A mudança organizacional aconteceu a partir do envolvimento de todos os funcionários dos setores e das sensibilizações realizadas pelo ecotime, principalmente pelo apoio demonstrado do diretor superintendente, que possibilitou o sentimento da necessidade de mudança.

O novo padrão implantado reduziu o uso de matéria-prima em $18 \%$ para cada unidade produzida de embalagem. A redução do volume de madeira anual consumida foi de 123,64 $\mathrm{m}^{3}$. A redução no custo anual das embalagens foi de $\mathrm{R} \$ 47.757,24$. Em média, a redução do custo por unidade de embalagem foi de $11 \%$.

Os pallets, embalagens de madeira utilizadas para unitizar a carga do mercado de exportação, também tiveram alterações que possibilitaram uma redução anual de $61,31 \mathrm{~m}^{3}$ de madeira serrada, somente nos modelos mais representativos da curva $A B C$, os quais tiveram seu 
projeto alterado. A redução no custo anual com os pallets de exportação foi próximo de 30 mil reais.

O índice de aproveitamento da madeira na serraria não chega a $25 \%$, onde são necessários 4,09 $\mathrm{m}^{3}$ de toras para gerar $1 \mathrm{~m}^{3}$ de madeira serrada. Com a utilização da máquina de aproveitamento, chegou-se a um índice de aproveitamento de madeira de $33 \%$ (3 $\mathrm{m}^{3}$ de toras para obtenção de $1 \mathrm{~m}^{3}$ de madeira serrada). A economia da operação com a compra da máquina de aproveitamento deu-se em termos de resíduos de madeira (costaneiras) que não foram descartados e sim transformados em matéria-prima para a caixaria (tábuas). Logo, a quantidade de matéria-prima comprada para produzir a mesma quantidade de caixas, foi reduzida. Os dados do fluxo líquido de caixa (entradas de caixa menos saídas de caixa) foram necessários para fazer as análises de lucratividade do projeto. A Figura 3 demonstra a representação gráfica do fluxo de caixa da proposta, cujo investimento da máquina de aproveitamento foi de $\mathrm{R} \$ 55.400,00$. A taxa mínima de atratividade (TMA) utilizada na empresa para análise econômico-financeira dos investimentos propostos é de $12 \%$ ao ano.

O cálculo do payback demonstra que o lucro líquido acumulado em 11 meses, através da compra da máquina de aproveitamento, é o tempo necessário para pagar o investimento. O resultado do cálculo do VPL (Valor Presente Líquido) foi maior que zero, isso significa dizer que o investimento é economicamente atrativo, pois o valor presente das entradas de caixa é maior do que o valor presente das saídas de caixa. O resultado da TIR foi maior do que a taxa mínima de atratividade, concluindo-se que o investimento é economicamente atrativo.

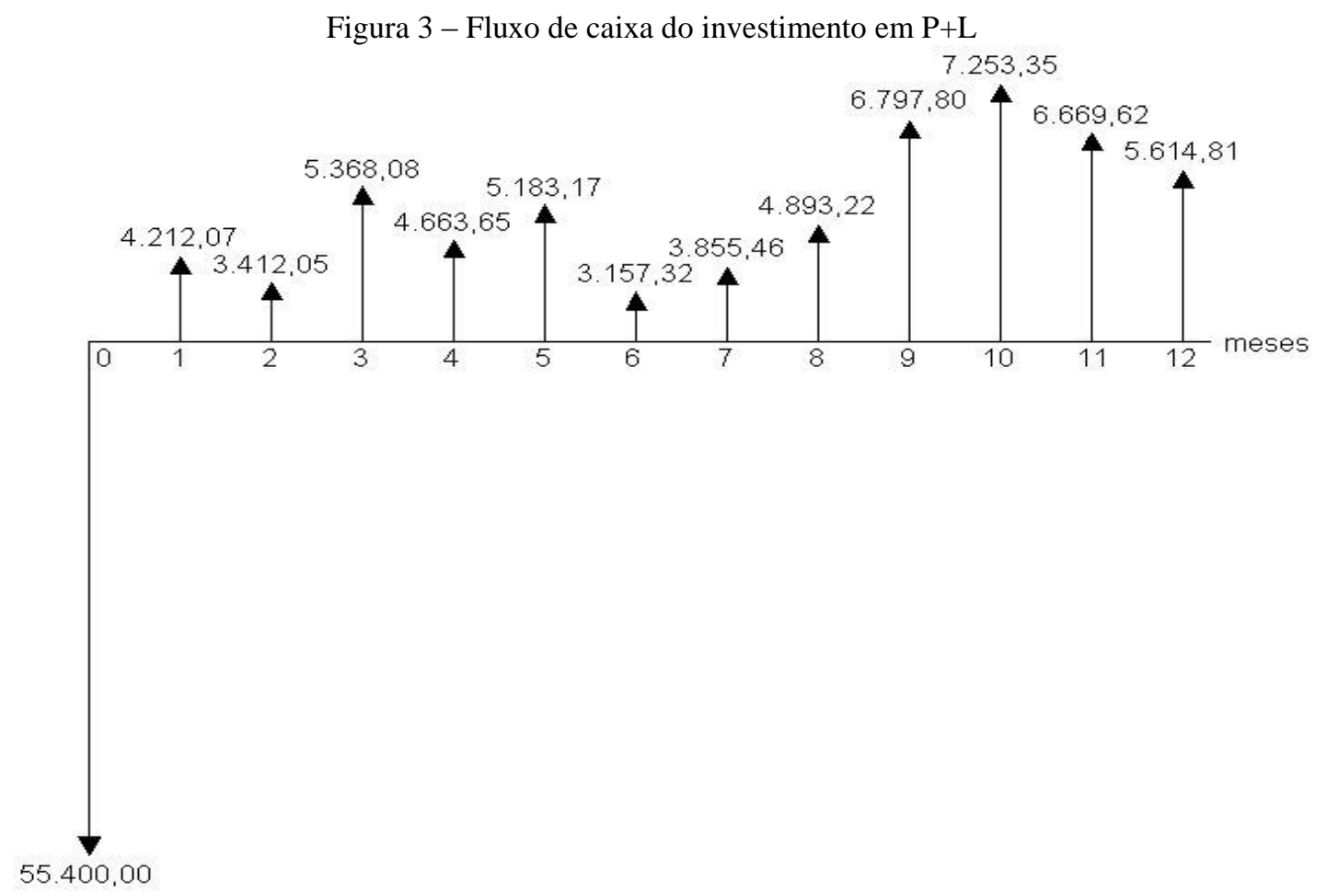

Fonte: Autoria própria (2011) 
$\mathrm{Na}$ avaliação ambiental, conclui-se que o maior ganho está relacionado com o melhor aproveitamento da matéria-prima, que proporcionou um aumento no índice de aproveitamento da madeira, reduzindo o consumo de toras de 4,09 para 3,00 $\mathrm{m}^{3}$. O resultado concreto foi a redução do resíduo gerado na forma de costaneiras, em $874,04 \mathrm{~m}^{3}$ anuais, o que equivale uma redução de 607,73 toneladas por ano. Analisando o balanço de massa, onde foram produzidas 2.257,89 toneladas ao ano, obteve-se uma economia financeira de $\mathrm{R} \$ 55.344,77$.

Com base nesse resultado, conclui-se que a quantidade de toras extraídas na unidade reflorestamento para produzir a mesma quantidade de produtos, pode ser menor. O valor gasto com plantio e extração de toras nessa unidade diminuiu consideravelmente, além de tornar-se ambientalmente mais eficiente, por aumentar a vida útil das toras.

O monitoramento realizado nos setores apontou que os funcionários absorveram as mudanças realizadas e, principalmente comprometeram-se com elas, pois constatou-se que as informações sobre as mudanças nos processos, a importância da redução de resíduos e uma postura voltada para $\mathrm{P}+\mathrm{L}$ estavam sendo repassadas aos novos funcionários contratados. Os indicadores apresentaram-se dentro dos limites de controle estabelecidos, comprovando assim, a eficácia do processo no decorrer do tempo.

\section{Conclusão}

O diagnóstico ambiental realizado nos setores de serraria e caixaria mostrou-se uma ferramenta decisiva na implementação de ações de redução do uso de matéria-prima e de redução da geração de resíduos.

A técnica aplicada utilizou os princípios de Produção mais Limpa desenvolvida pelo CNTL e mostrou-se eficiente, pois possibilitou a redução, na fonte, dos resíduos gerados nos setores. Essa medida melhorou o aproveitamento da matéria-prima, aumentando a vida útil das toras na unidade reflorestamento, aumentando a competitividade da empresa pela racionalização dos processos e pela redução do impacto ambiental e dos custos produtivos. De fato, é possível perceber que o sucesso do projeto se deu em função da participação e envolvimento de todos os funcionários com as metas e objetivos estabelecidos e, constatou-se que esse envolvimento foi possível através das atitudes empregadas durante a implementação, que fizeram com que as pessoas realmente sentissem a necessidade de mudar e, a partir de então, engajaram-se com o projeto.

As pessoas e a comunicação são o cerne de toda a transformação organizacional. Não há como dissociar das pessoas a responsabilidade por mudar, mesmo que haja total entrega dos gestores e dos líderes envolvidos. A participação do diretor superintendente foi decisiva para que todos os funcionários se sentissem valorizados, e também para quebrar a barreira da resistência. Certamente, a excursão realizada na fazenda contribuiu para o comprometimento dos funcionários, 
uma vez que eles puderam observar e compreender de uma forma mais clara o valor de cada função. Promover a quebra da rotina e principalmente, celebrar pequenas vitórias durante o projeto, fortaleceu toda a equipe, que conseguiu permanecer engajada na busca do cumprimento dos objetivos e da meta do projeto.

Os resultados obtidos, em especial o aumento efetivo do uso da matéria-prima, e consequentemente a redução de resíduos de madeira em aproximadamente $26 \%$, demonstram que o enfoque preventivo deve ser prioritário na busca da redução do impacto ambiental causado pelos processos produtivos. Ressalta-se também que a $\mathrm{P}+\mathrm{L}$ não só possibilita alcançar benefícios ambientais, como também benefícios econômicos, fundamentais para promoção de práticas ambientalmente corretas e para sustentabilidade da empresa, dos stakeholders e de todo o planeta.

As alterações propostas possibilitaram uma melhoria importante da eficácia operacional e uma melhor utilização dos recursos naturais, criando vantagem competitiva para a organização e agregando novos conhecimentos aos profissionais ligados ao projeto. As dúvidas e dificuldades encontradas durante a realização do trabalho foram compartilhadas, superadas e integram a mudança organizacional ocorrida na empresa. A aprendizagem e a mudança organizacional promovidas são consistentes com a nova cultura da empresa, que defende a sustentabilidade e passou a gerenciar e controlar verticalmente o seu recurso natural, a madeira, bem como o seu beneficiamento. A direção da empresa parece estar alinhada com o perfil pró-ativo de sustentabilidade, "pense globalmente, aja localmente" (WALTER, 2004; COLLINS; KEARINS, 2010).

Na conclusão do estudo realizado por Baas (2007) ressaltou-se que os projetos de Produção mais Limpa iniciam com entusiasmo, mas que, passado algum tempo, a atenção vai se diminuindo em função da complexibilidade, do tempo necessário e dos custos para resolver o problema. $\mathrm{O}$ autor também acrescenta que a falta de consciência e conhecimento sobre a gestão da mudança faz com que, a maioria dos projetos, limita-se a abordagens técnicas; dificilmente se incluindo as dimensões sociais e psicológicas da mudança organizacional e com isso, dificultando o alcance dos resultados esperados. Essa colocação reforça que o sucesso da implantação das técnicas de P+L no estudo de caso apresentado se deu, em grande parte, pelo empenho da equipe em envolver os funcionários e os gestores num sentimento de colaboração e participação, estabelecendo o processo de mudança organizacional nos setores.

Sugere-se que outros programas de $\mathrm{P}+\mathrm{L}$ sejam incentivados na empresa e nas demais unidades de negócio da organização, explorando o caso aplicado nos setores estudados. Conforme colocado por Baas (2007) é de extrema importância à disseminação das práticas de $\mathrm{P}+\mathrm{L}$, pois as evidências das experiências positivas de uma empresa individual levam, automaticamente, à cópia rápida e generalizada por outras organizações. 


\begin{abstract}
The companies like transforming raw materials into products have great responsibility in protecting, handling and use of natural resources. Thus, all efforts seeking to promote sustainable development should be a priority. In this context, the aim of this article is to describe and evaluate the impact of using cleaner production techniques in the performance of the sectors sawmill and manufacturing of packaging boxes in a electric motors company. The research is a qualitative approach with descriptive purpose. The technical procedure used was the case study. The conclusion of the analysis of the results was that the use of this tool was crucial to reducing waste in production processes, highlighting the environmental and economic benefits of the implementation of Cleaner Production Technique and how its boosted the organizational change in the company studied, mainly by the involvement of all employees in the process and small changes implemented during the project.
\end{abstract}

Key-words: cleaner production; organizational change; sustainable development.

\title{
Referências
}

BAAS, L. To make zero emissions technologies and strategies become a reality, the lessons learned of cleaner production dissemination have to be known. Journal of Cleaner Production. n. 15, p. 1205-1216, 2007. crossref

BERKEL, R. Cleaner production and eco-efficiency initiatives in Western Australia 1996 - 2004. Journal of Cleaner Production, n. 15, p. 741-755, 2007. crossref

BRUNO-FARIA, M. F. Criatividade, inovação e mudança organizacional. In: Lima, S. M. V. (Org.). Mudança Organizacional: teoria e gestão. Rio de Janeiro: FGV, 2003.

CERVO, A. L.; BERVIAN, P. A.; SILVA, R. Metodologia científica. 6. ed. São Paulo: Pearson Prentice Hall, 2007.

COLLINS, E. M.; KEARINS, K. Delivering on sustainability's global and local orientation. Academy of Management Learning \& Education, v. 9, n. 3, p. 499-505, 2010. crossref

CONSELHO EMPRESARIAL BRASILEIRO PARA O DESENVOLVIMENTO SUSTENTÁVEL - CEBDS. Guia de Produção mais Limpa: faça você mesmo. Rio de Janeiro, 2001. Disponível em: 〈http://www.cebds.org.br〉. Acesso em: 02 jul. 2011.

COMPANHIA DE TECNOLOGIA DE SANEAMENTO AMBIENTAL - CETESB. Prevenção à poluição. São Paulo, 2001. Disponível em: <http://www.cetesb.sp.gov.br>. Acesso em: 02 jul. 2011.

CENTRO NACIONAL DE TECNOLOGIAS LIMPAS - CNTL. Implementação de programas de Produção mais Limpa. Porto Alegre, 2007.

FORD, J. D.; FORD, L. W. The role of conversations in producing intentional change in organizations. The Academy of Management Review, v. 20, n. 3, p. 541-570, 1995.

HILLIG, É.; SCHNEIDER, V. E.; PAVONI, E. T. Pólo moveleiro da serra gaúcha: geração de resíduos e perspectivas para sistemas de gerenciamento ambiental. Caxias do Sul: Educs, 2004.

HINZ, R. T. P.; VALENTINA, L. V. D.; FRANCO, A. C. Monitorando o desempenho ambiental das organizações através da Produção mais Limpa ou pela avaliação do ciclo de vida. Revista Produção, Florianópolis, v. 7, n. 3, p. 9198, 2007.

KOTTER, J. P. Leading change: why transformation efforts fail. Harvard Business Review, mar.-apr. p. 59-67, 1995.

KOTTER, J. P.; COHEN, D. S. O coração da mudança. Rio de Janeiro: Campus, 2002.

LEWIN, K. Field theory in social science. Nova York: Harper \& Row, 1951. 
MARTINS, G. de A.; THEÓPHILO, C. R. Metodologia da investigação científica para ciências sociais aplicadas. 2. ed. São Paulo: Atlas, 2009.

NADLER, D. A.; SHAW, R. B.; WALTON, A. E. Discontinuous change: leading organizational transformation. San Francisco: The Jossey-Bass, 1994. (Management Series, 2).

PETTIGREW, A. M. Theoretical, methodological, and empirical issues in studying change: a response to starkey. Jounal of Management Studies, v. 24, n. 4, p. 420-426, 1987.

PROGRAMA DAS NAÇÕES UNIDAS PARA O MEIO AMBIENTE - PNUMA. A Produção mais limpa e o consumo sustentável na América Latina e Caribe. São Paulo, 2004. Disponível em: 〈http://www.pnuma.org>. Acesso em: 6 jul. 2011.

PORRAS, J. J.; ROBERTSON, J. Organizational development: theory, practice, and research. In: Dunnette, M. D.; Hough, L. M. (Eds.). Handbook of Industrial and Organizational Psychology. Palo Alto, Califórnia: Consulting Psychologists Press, 1992.

ROBBINS, S. P. Comportamento organizacional. 8. ed. Rio de Janeiro: LTC, 1999.

SCHNEIDER, V. E.; NEHME, M. C.; BEN, F. Pólo moveleiro da serra gaúcha: sistemas de gerenciamento ambiental na indústria moveleira. Caxias do Sul: Educs, 2006.

WALTER, S. Think global, act local. Edinburgh: Luath Press, 2004.

WOOD JR., T. Mudança organizacional: liderança, teoria do caos, qualidade total, recursos humanos, logística integrada, inovações gerenciais, cultura organizacional. 2. ed. São Paulo: Atlas, 2000.

YIN, R. K. Estudo de caso: planejamento e métodos. 3. ed. Porto Alegre: Bookman, 2005.

ZENG, S. X. et al. Impact of cleaner production on business performance. Journal of Cleaner Production, n. 18, p. 975-983, 2010. crossref

\section{Dados dos autores}

\section{Nome completo: Michele Otobelli Bertéli}

Filiação institucional: Universidade de Caxias do Sul

Função ou cargo ocupado: Mestranda no Programa de Pós-Graduação em Administração da Universidade de Caxias do Sul

Endereço completo para correspondência: Rua: João Manuel Guedes Falcão, 80, Bairro: Madureira, Cep: 95041-670, Caxias do Sul/RS

Telefone para contato: (54) 9901.0877

e-mail: micheleberteli@gmail.com

Nome completo: Paulo Fernando Pinto Barcellos

Filiação institucional: Universidade de Caxias do Sul

Departamento: Programa de Pós-graduação em Administração (PPGA)

Função ou cargo ocupado: Professor do Corpo Permanente do PPGA, responsável por Relações Acadêmicas Exteriores 
Endereço completo para correspondência: Rua: Francisco Getúlio Vargas, 1130, Bairro: Petrópolos, Cep: 95070-560, Caxias do Sul/RS

Telefone para contato: (51) 9955.5262

e-mail:PFPBarce@ucs.br

Nome completo: Margareth Rodrigues de Carvalho Borella

Filiação institucional: Universidade de Caxias do Sul

Departamento: Centro de Ciências da Administração

Endereço completo para correspondência: Rua: Francisco Getúlio Vargas, 1130, Bairro: Petrópolos, Cep: 95070-560, Caxias do Sul/RS

Telefone para contato: (54) 3218-2174

e-mail:mrcborel@ucs.br

Submetido em: 24/09/2012

Aceito em: 18/12/2013 